\title{
Study on Planning and Construction of Community Greenway for PM2.5 Reduction
}

\author{
Lijun $\mathrm{Hao}^{1,2}$, Zhetao Xiao ${ }^{2}$ and Qiusheng Yang ${ }^{*}, 1$ \\ ${ }^{1}$ College of Forestry, Henan Agricultural University, Zhengzhou, 450002, China \\ ${ }^{2}$ College of Architecture, North China University of Water Resources and Electric Power, Zhengzhou, 450046, China
}

\begin{abstract}
In the developing process of urbanization in China, PM2.5 pollution has become a problem that must be faced. Greenway, especially those in the community, is the important green infrastructure to improve ecological environment in urban areas, which plays a crucial role in PM2.5 reduction. With basic cognitive analysis on definitions and characteristics of community greenway and PM2.5, this paper proposed the strategy on planning and construction for greenways in community to reduce PM2.5 from four aspects including subarea construction, construction elements, allocation of afforestation plants and injection of regional culture, hoping to benefit the construction of greenways in community.
\end{abstract}

Keywords: Community greenway, PM2.5, Strategy on planning and construction.

\section{INTRODUCTION}

\subsection{Community Greenway}

Greenway construction was originated in the United States, Which is in the positive development all around the world. China's massive construction of greenways rose in 2010, marked by promulgation of Outline on Overall Plan for Greenway Network in Pearl River Delta and construction practices in nine cities of Pearl River Delta, as shown in Fig. (1). Greenways build a green network system covering the entire area where people live and work, which can connect valuable natural and cultural resources in organic manners. Greenway has multiple functions on ecology, society, economy and culture. Especially for the ecological function, it provides sufficient space for growth of plants and multiplication and habitat of animals, helps to protect natural environment in better ways and also provides ventilation corridors for urban areas to alleviate the heat island effect. Besides, it plays a role in flood prevention, soil fixation, clean water sources and air cleaning. And good adsorption ability of plants is an effective method to reduce PM2.5.

Greenways can be divided into regional greenways, urban greenways and community greenways. Community greenways refer to those connecting community parks, small gardens and street green patches provided for the community residents in neighborhood with service. Community greenway is the smallest unit in the greenway network system, playing a role similar to "capillary". Community greenways near the community are those in small scale and at low levels with easy access to the surrounding residents, they meet the needs of surrounding residents on leisure and relaxation and take into account the ecological function [1].
On aspects of theory and practice, studies on urban greenway and regional greenway are in a relatively large number in China, but studies on community greenway are still at the initial stage. Li Qiucui [2] (2011) studied the postevaluation on practice and application of greenways at the community level. Huangjing [1] (2011) proposed the design concept combining community greenway with urban functions, design principles, nodes and detail design for community greenway. Chen Fumei et al. [3] (2012) summarized the characteristics, principles and other factors relating to plan for community network. Yaorui [4] (2012) proposed that community should establish and improve urban-park green-patch system and urban slow-lane system, conduct rational distribution for community greenway system, set up service radius by grades, and adopt different construction standards according to actual conditions. Lai Shouhua et al. [5] (2012) pointed out that community greenway in compact cities was the new trend for greenway construction. In practice, plan and construction of greenways in Pearl River Delta still stay at the phase of greenway network construction basically on levels of regional greenway and urban greenway. For the community greenway playing a role of "capillary", there are few specialized plans and technical guidelines and lack of instances in a large number, which were only mentioned on the level of urban greenway in some cities. For example, Overall Plan on Greenway Network in Haizhu District of Guangzhou, put forward the tentative plan on construction of community greenway under the layout structure of "water as the vein, circle the island; park as the core, string green patches into network", which identified the green slow-lane network consisting of regional (provincial) greenway, urban greenway and community greenway. However, this plan is still in the stage of framework building due to the short time of construction, where association between greenway and urban life and the role of community greenway in reducing PM2.5 need to be further researched, this is shown in Fig. (2) [5].

2015 Bentham Open 


\subsection{PM2.5}

PM2.5 is the fine particulate matter, mainly referring to particles in the ambient air with diameter of aerodynamic equivalent less than or equal to 2.5 micron, also known as repairable particles. PM2.5 has small particle diameter and a lot of toxic and hazardous substances that can remain in the atmosphere for a long time and transport for distance, which has a great impact on human health and environmental quality of the atmosphere. Major sources of PM2.5 include emissions from factories, vehicle exhaust emissions, incomplete combustion of fuel, unhealthy lifestyles of people in high density (such as smoking) and so on.

In addition, main components of PM2.5 are water-soluble molecules, which lead to great changes on the concentration along with seasons. Generally, concentration of PM2.5 is lower in summer due to large amount of rainfall and higher in winter due to dry air. For urban areas, concentration of PM2.5 is significantly high because of large density of buildings, poor ventilation, automobile exhaust and gathering of many industrial plants.

\section{THINKING ON PLANNING \& CONSTRUCTION OF COMMUNITY GREENWAY TO REDUCE PM2.5}

As a result of characteristics taken on by PM2.5, China is vigorously promoting green transportation in order to reduce the generation and emission of PM2.5. To reduce PM2.5 by encouraging people to take more public transportation and drive less is imperative under the situation. How to create a way not only convenient for people's transportation but also environmentally friendly is an issue many Chinese experts and scholars think about. As the "last mile" section connecting to public transportation transfer, community greenway arouses our considerations on its accessibility, security, convenience and even the guidance.

Combined with the relevant characteristics of PM2.5, planning and construction of community greenway shall take into consideration to control sources of PM2.5, reduce pollution sources, prevent diffusion, narrow the scope of contamination, control measures on effective absorption and collection, use of the utilization methods, plan guidance, transport organization, plant disposition and landscape building to reduce PM2.5 pollution in our residential microenvironment, in a way to mitigate pollution and deal with pollution caused by harmful PM2.5 [6].

\section{PLANNING \& CONSTRUCTION STRATEGIES FOR COMMUNITY GREENWAY TO REDUCE PM2.5}

\subsection{Subarea-Based Construction to Restrain Sources of PM2.5}

During planning and construction of community greenway, we should take full advantage of existing green space such as community roads, square green patches, river

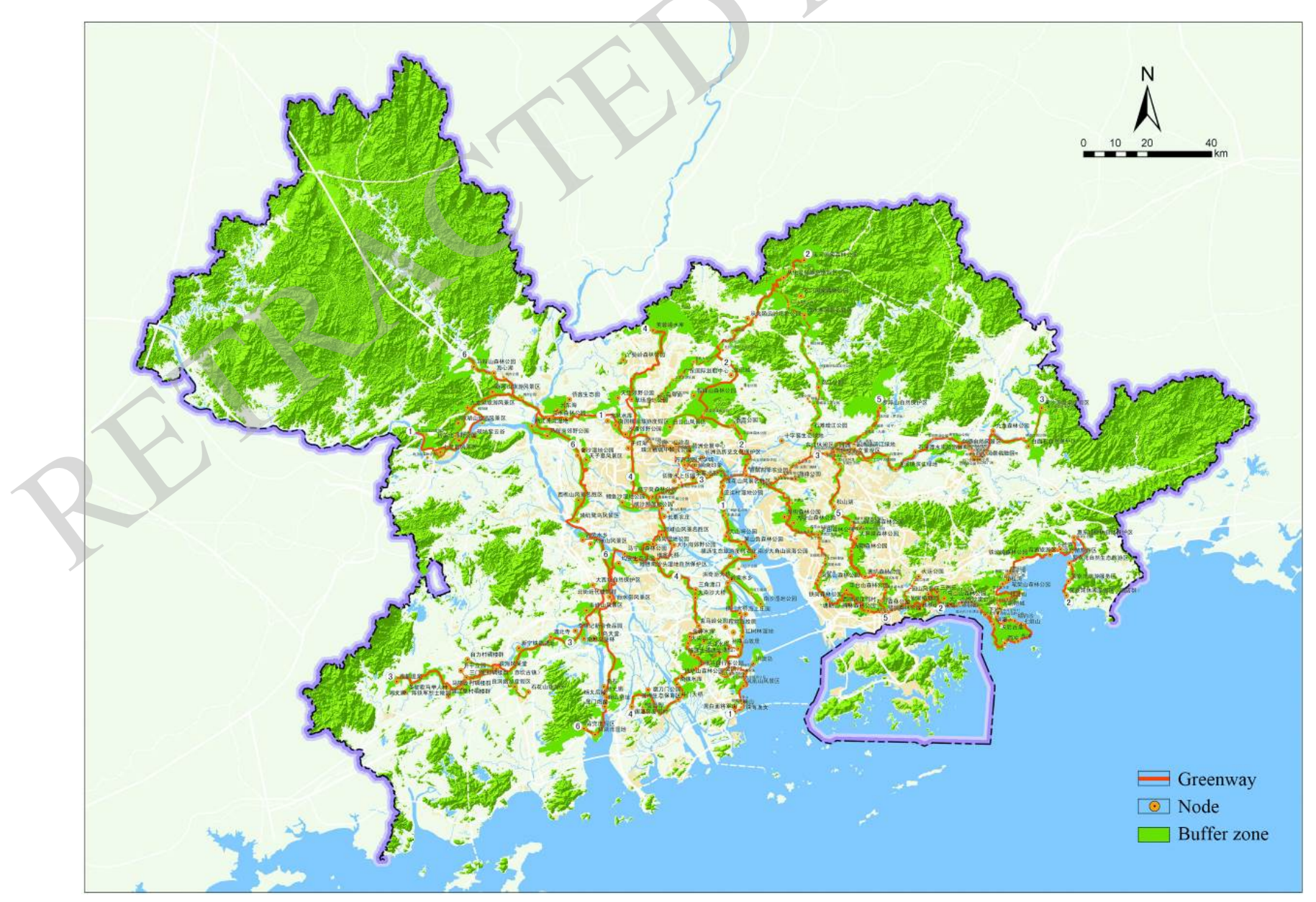

Fig. (1). The schematic diagram of greenway network in Pearl River Delta. 


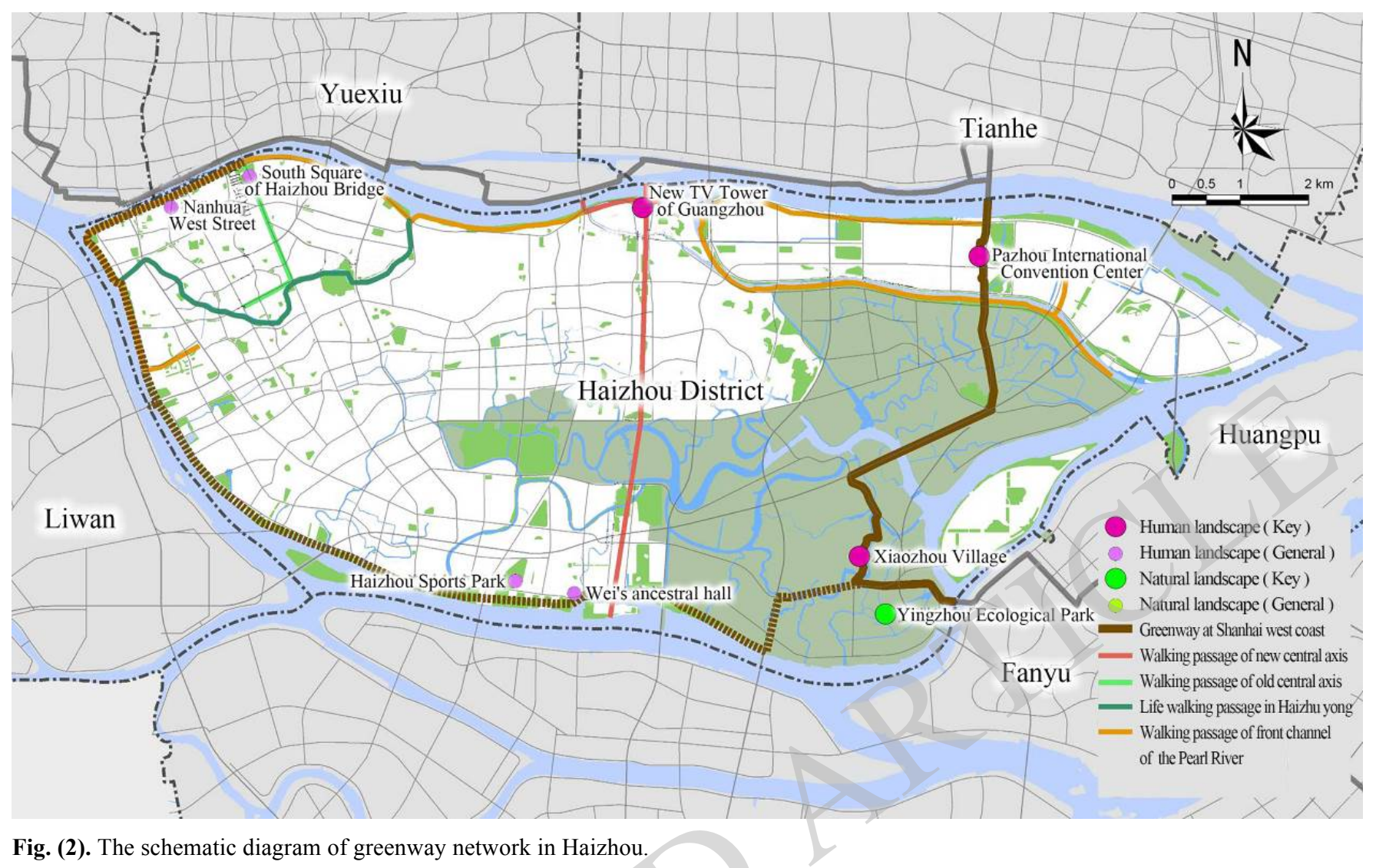

embankments and other places, make reasonable layout for green channels, excavate the existing green space, and improve practicality and participation of planning and construction for community greenway [7].

Based on consideration for equalization of service, we should comprehensively plan layout trend of the community greenway, design line network and density of the community greenway in reasonable manners, connect group types and grades of planning and construction for different community greenways. We should plan for community greenway spaces in categories and grades, taken into account the various construction stages and different construction areas, prevent motorized vehicles going on community greenways, which may bring adverse effects on safety of residents and increase PM2.5 emissions. Conduct scattered layout for public spaces in the community greenway and avoid massive crowd being gathered on the use of space. Adopt wet cleaning for internal and peripheral areas of the community greenway and restrain production and circulation of PM2.5 from the source.

\subsubsection{Inside Community or Division}

Users and hierarchy shall be considered for construction of community greenway inside community or division to ensure smooth passage of residents on foot and by bike. Promote and strengthen exchanges among users of the community or division, improve traffic environment, create comfortable, safe and green channel with planning measures, where low-carbon green traffic acts as the important part in reducing PM2.5. Efforts should be made to expand planning and construction along the green open space and combine with existing green square and landscape water inside the division. Moreover, properly narrow the scope and scale of lumping green patches, expand them into the community greenways through width expansion, promote people to access and use more conveniently, as shown in Fig. (3). In this way, we can improve efficiency in the use of green space and also restrain the generation of PM2.5.

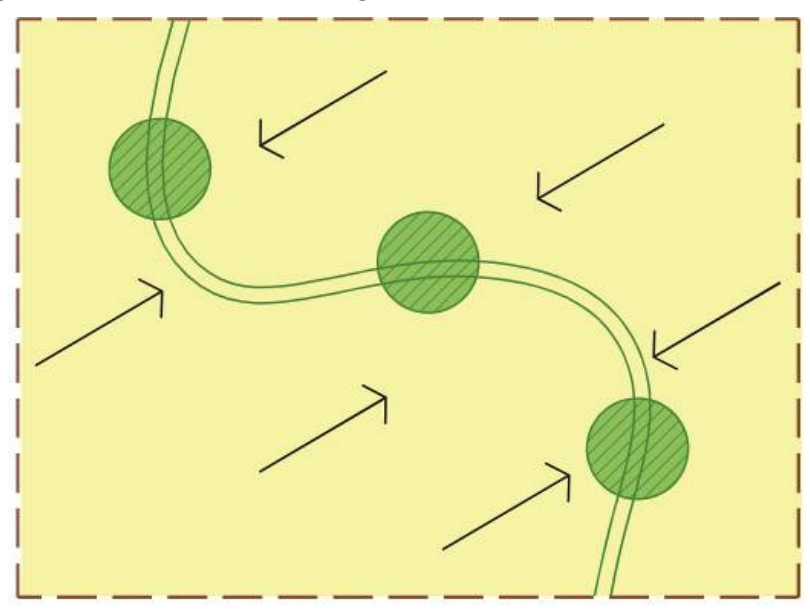

More convenient access and use for people

Green square and landscape water

\section{$\curvearrowright$ Community greenway}

- - - The boundary of community or division

Fig. (3). The model of community greenway inside community or division. 


\subsubsection{Among Communities}

Urban communities are relatively independent and divided by walls, where people have few opportunities to communicate with each other. It is essential to build up community greenways for promoting interaction among people in different communities. Realize effective connection among parks, green patches and squares at center of the community with planning and construction for community greenways. While utilizing current green patches and squares, enlarge space of the dedicated greenway, shorten vehicle connection distance among communities, expand them into green channels for walk or bike under layout, which will not only cut the source of PM2.5 generated by vehicles, but also ensures accessibility and continuity among communities, as, illustrated in Fig. (4).

\subsubsection{Among Residential Areas and Business Districts}

Going to the business districts for shopping accounts is a large proportion of people's daily trips. Thus, there is increase demand for non-motor vehicle roads. Undoubtedly, building up non-motor vehicle roads for walk or bike to connect residential areas and secondary business districts nearby is an essential mode for planning of community greenways. Particular attention should be paid to make reasonable layout for community greenways along green square, green patch groups, street green patches and commercial pedestrian streets, which will increase the roads for non-motor vehicles, help reduce the use of motor vehicles, keep PM2.5 within limits and provide a pleasant way to travel, as shown in Fig. (5).

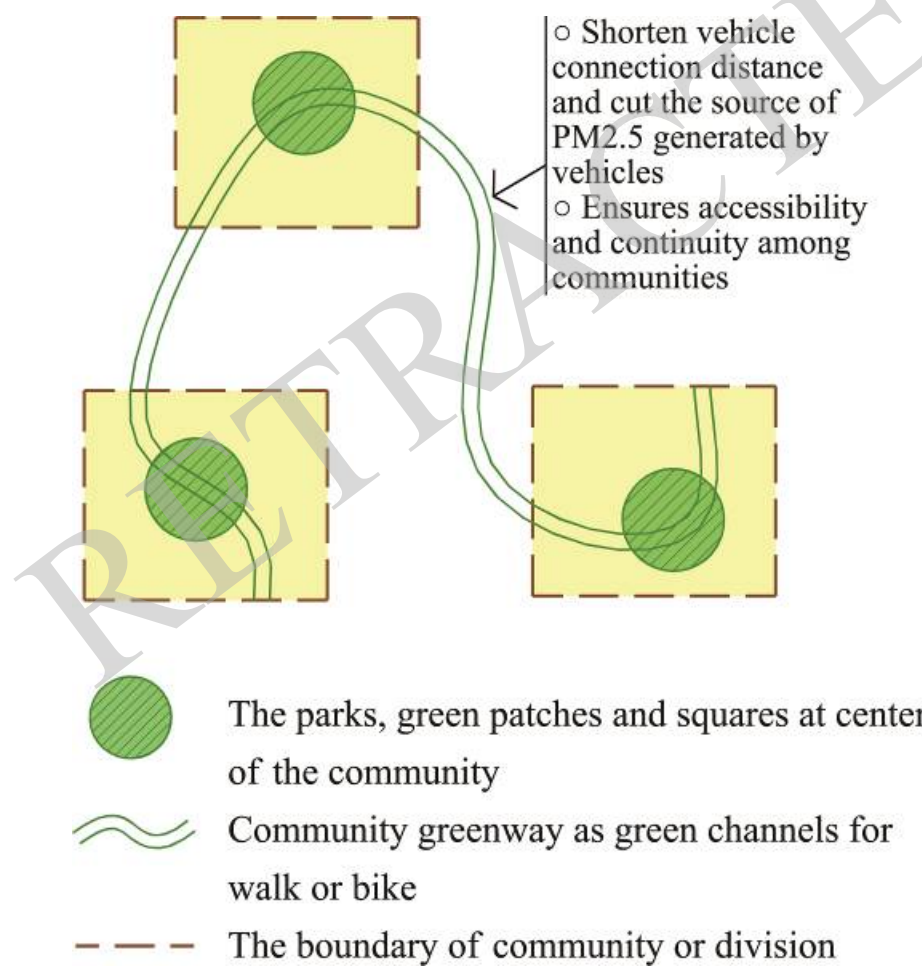

Fig. (4). The model of community greenway among communities.

\subsubsection{Among Community, Park \& Square}

Now, we are living in an era of leisure, when "slow life" has been observed of people after work. To build community passages among urban park squares and residential areas, as this model is illustrated in Fig. (6), can create an atmosphere in front of entering the park's entrance square, further extend landscape of the park \& square towards community and form a pedestrian network system which is safe and efficient. In this way, rate of travelling by motor vehicles can be cut down, leading to emission reduction and natural reduction in PM2.5.

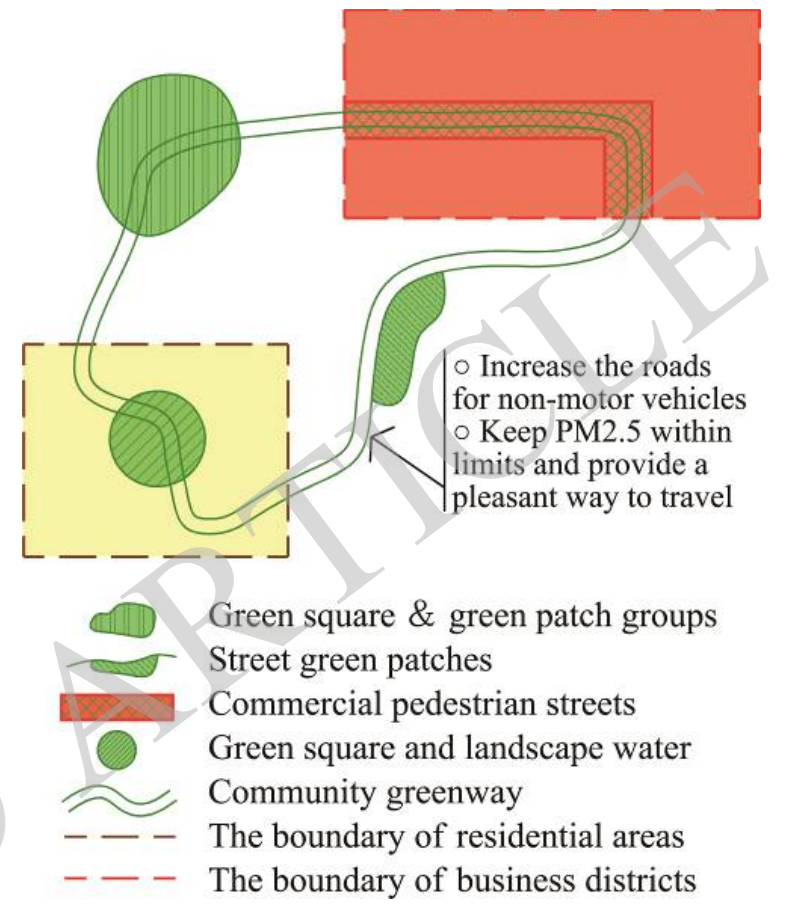

Fig. (5). The model of community greenway among residential areas and business districts.

\subsubsection{Communities on Urban Fringe}

It is difficult to build up community greenways inside the urban area where regional construction has been finished. And for areas on urban fringe under construction, building up community greenways will be relatively simple. Reasonable planning and construction of community greenway network on urban fringe could ensure good nonmotor vehicle passages to be built even after expansion of the scale, as shown in Fig. (7). From a long-term and strategic perspective, such a layout mode is just to restrain the production of PM2.5.

\subsubsection{Among Communities on Urban Fringe and Suburbs}

To enhance the relation with communities on urban fringe and suburbs that is important, this is good for urbanrural integration development. Community greenway is the bridge of urban and rural landscape infiltration as this model is illustrated in Fig. (8).

It is suggested to realize spatial connection between community greenway and green patches on urban fringe to form an organic green channel system for non-motor vehicles which can reduce the PM2.5, extend natural landscape into urban area and improve the regional greenway network. 


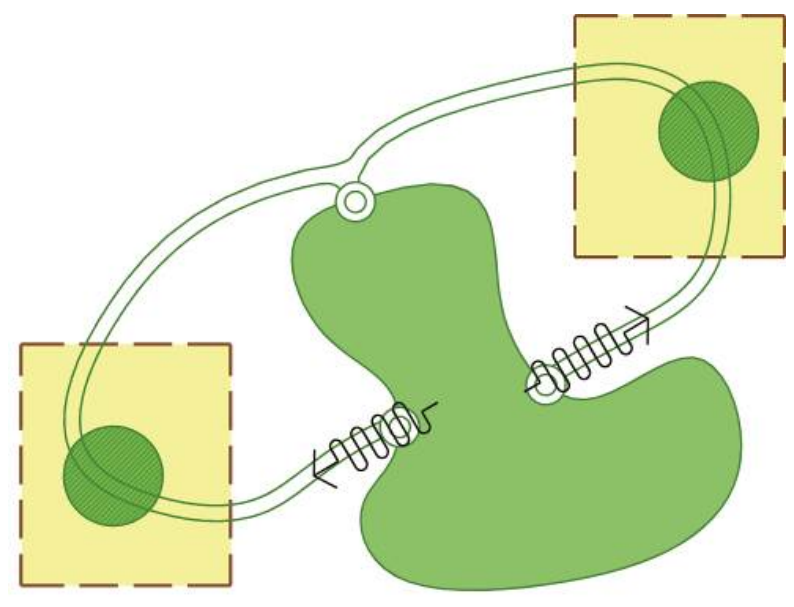

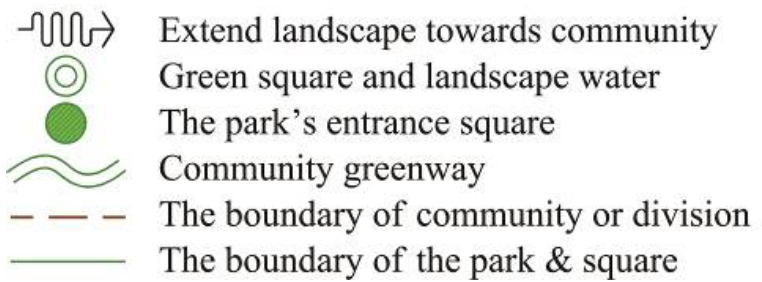

Fig. (6). The model of community greenway among community, park \& square.

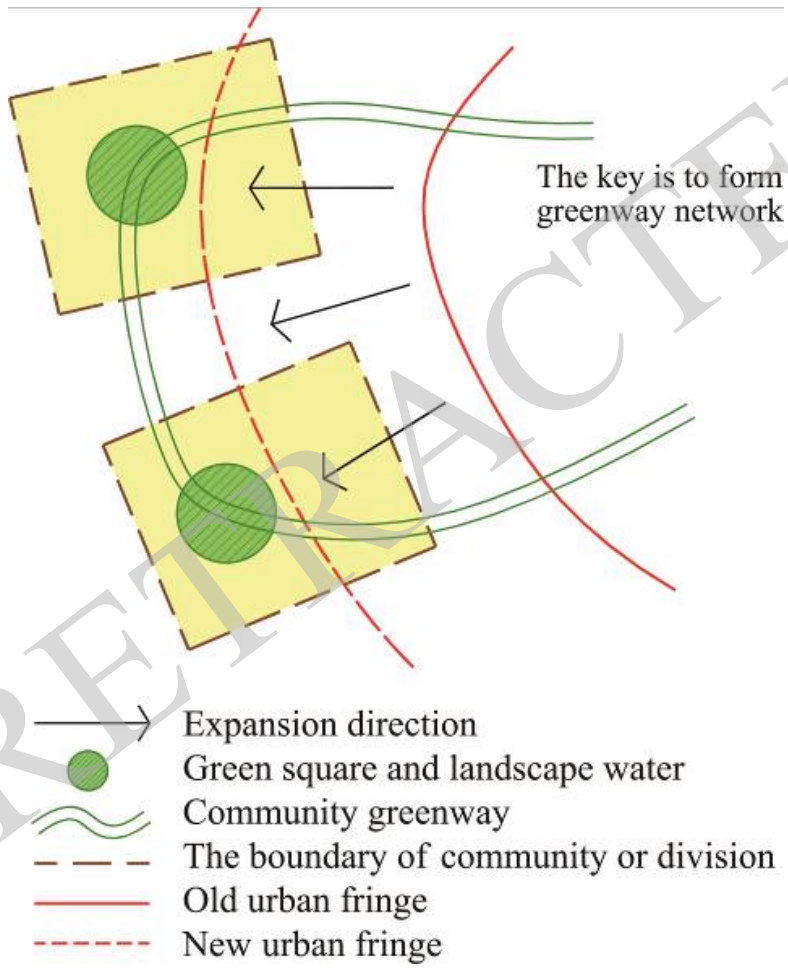

Fig. (7). The model of community greenway on urban fringe.

\subsection{Integrate the Construction Elements of Community Greenway and the Measures for PM2.5 Reduction}

Planning and construction of community greenway include 5 systems and 17 elements [5]. The 5 systems include slow traffic system, traffic engagement system, service facility system, identification system and lighting system. The 17 elements include walking passage, bicycle path, comprehensive slow lane, non-motor vehicle bridge, line and signal light at intersection, bike stop, bicycle rent, recreational facilities, science education facilities, security facilities, environmental sanitation facilities, information signs, directional sign, regulation sign, warning sign, space lighting and green lighting. Different measures should be taken to reduce PM2.5 for planning and construction, aiming at different elements within five systems, as shown in Table $\mathbf{1 .}$

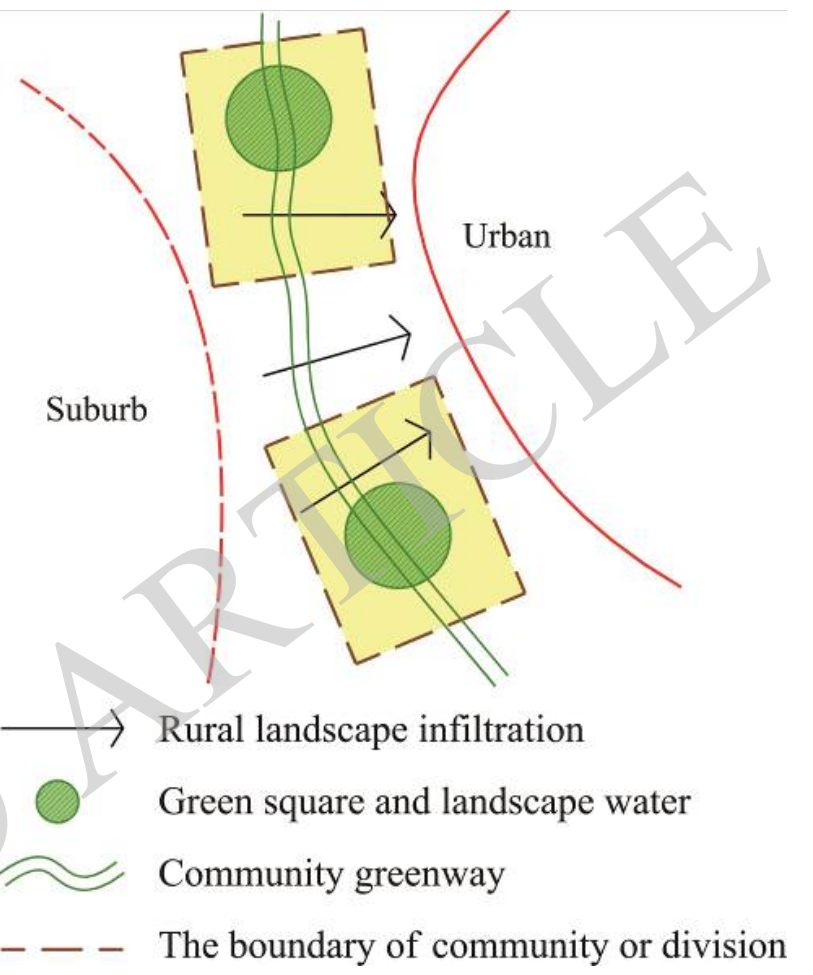

Fig. (8). The model of community greenway among communities on urban fringe and suburbs.

For slow traffic system, the measures to reduce PM2.5, mainly consider the way for non-motor vehicles that is reasonable density, width and scale to promote use. For traffic engagement system, the key point is to plan appropriate non-motorized facilities and smooth intersection. For service facility system, the service facility must have a reasonable number and location, and build intelligent sanitation facilities as much as possible. Identification system should be clearly visible, lighting system should use solar and other clean energy, all these are the effective measures to reduce PM2.5

\subsection{Rational Allocation of Green Vegetation to Promote Adsorption \& Collection of PM2.5}

Studies have shown that leaves can fix and absorb particulate matter in the atmosphere. Trees with large and dense crown, hairy and fat or coarse leaf surface and secretion of grease or mucus have strong capacities on dust catching. Leaves with rougher surface have stronger capacities on catching and intercepting fine particulate matter in the air. Meanwhile, trees which build up shaded space can lower air temperature by evaporation, effectively improve environmental quality, increase local humidity to form a local micro-climate, thereby reduce emissions of 
Table 1. General list on elements for community greenway construction \& measures for PM2.5 reduction.

\begin{tabular}{|c|c|c|c|c|}
\hline System Name & Basic Elements & Setup Requirements & Remarks & Measures to Reduce PM2.5 \\
\hline \multirow{3}{*}{$\begin{array}{l}\text { Slow traffic } \\
\text { system }\end{array}$} & Walking passage & $\bullet$ & & \multirow{3}{*}{$\begin{array}{l}\text { Comprehensive consideration } \\
\text { on density, width and scale to } \\
\text { promote the rational use. }\end{array}$} \\
\hline & Bicycle path & $\circ$ & & \\
\hline & Comprehensive slow lane & $\circ$ & & \\
\hline \multirow{3}{*}{$\begin{array}{l}\text { Traffic } \\
\text { engagement } \\
\text { system }\end{array}$} & Non-motor vehicle bridge & ० & & \multirow{3}{*}{$\begin{array}{l}\text { - Appropriate non-motorized } \\
\text { facilities; } \\
\text { - Smooth intersection and } \\
\text { reduce haze caused by parking } \\
\text { of motor vehicle. }\end{array}$} \\
\hline & Line and signal light at intersection & - & & \\
\hline & Bike stop & $\bullet$ & & \\
\hline \multirow{5}{*}{$\begin{array}{l}\text { Service facility } \\
\text { system }\end{array}$} & Bicycle rent & $\bullet$ & & \multirow{5}{*}{$\begin{array}{l}\text { - Locations for rent, planned in } \\
\text { a reasonable number; } \\
\text { - Propaganda on PM2.5 } \\
\text { included into science education } \\
\text { facilities; } \\
\text { - Construction of anti-haze } \\
\text { facilities; } \\
\text { - Intelligent sanitation facilities } \\
\text { to reduce pollution }\end{array}$} \\
\hline & Recreational facilities & $\bullet$ & $\begin{array}{l}\text { Including cultural \& sports venue, leisure } \\
\text { station and etc. }\end{array}$ & \\
\hline & Science education facilities & ० & $\begin{array}{c}\text { Including science education facilities, } \\
\text { interpretation facilities, exhibition facilities } \\
\text { and etc. }\end{array}$ & \\
\hline & Security facilities & $\circ$ & $\begin{array}{l}\text { Including security \& fire-fighting station, } \\
\text { first-aid station, security and surveillance } \\
\text { facilities, accessibility and etc. }\end{array}$ & \\
\hline & Environmental sanitation facilities & ○ & $\begin{array}{c}\text { Including toilet, trash, sewage collection, } \\
\text { pollution discharge or simple treatment } \\
\text { facilities }\end{array}$ & \\
\hline \multirow{4}{*}{$\begin{array}{l}\text { Identification } \\
\text { system }\end{array}$} & Information signs & $\circ$ & & \multirow{4}{*}{$\begin{array}{l}\text { - Clearly visible signs to } \\
\text { enhance the using effect of } \\
\text { community greenways }\end{array}$} \\
\hline & Directional sign & $\circ$ & C & \\
\hline & Regulation sign & $\circ$ & & \\
\hline & Warning sign & & & \\
\hline \multirow{2}{*}{ Lighting system } & Space lighting & 0 & & \multirow{2}{*}{$\begin{array}{l}\text { - Use solar and other clean } \\
\text { energy }\end{array}$} \\
\hline & Green lighting & 0 & & \\
\hline
\end{tabular}

Note: $\bullet$ the project must be built, $\circ$ the project was built when conditions permit or require.

pollutants in ways of saving energy consumption for cooling $[8]$.

It is suggested to select native tree species with absorption capacities for rational allocation of vegetation, forming a mode of shrub and arbor in horizontal close planting and vertical contact, which will absorb and collect PM2.5 and also build up specific landscape system for community greenways, such as ligustrum lucidum, oleander, michelia longifolia and euonymus as shrubs; Chinese parasol, elm, paulownia, sophora japonica, American elm, locust and magnolia grandiflora as arbor. Meanwhile, advocate vertical afforestation in community greenways, build wall and roof afforestation, plant vines on walls outside the building, terrace, outdoor fences and other places to form a green barrier.

\subsection{Inject Geographical and Cultural Connotations in the Community Greenway To improve Overall Quality of the Residents on PM2.5 Reduction}

With the rapid development of urbanization, lack of regional culture appears in many cities. At initial stage of planning and construction for community greenways, we should fully excavate and stress natural and cultural features of local areas, exhibit local context, respect local customs and highlight cultural connotation with regional characteristics. On one hand, respect differences in climate, vegetation and topography between southern and northern parts, select more native plants and treat in accordance with local conditions. On the other hand, inherit and follow cultural and urban contexts of local areas to some extent, select more landscape sketches rich of historical and cultural features as carriers of ideal condition, to meet people's spiritual and cultural needs.

In addition, geographical and cultural construction of community greenways can play a role in gathering people, increasing vitality of space environment and improving people's cultural life. There is more propaganda on geographical culture and guidance for lifestyle in low-carbon and environmental manners at nodes with large streams of people. People can obtain a more profound understanding on PM2.5 reduction with space carriers. Not only inherit regional culture in planning and construction of community greenways, but also stimulate vitality of outdoor and public space for communication, to avoid the embarrassment on stereotyped outside space, form new space places rich of vitality, thus make them into propaganda front for community's culture. 


\section{CONCLUSION}

Atmospheric deterioration represented by PM2.5 acts a challenge for planning of spatial patterns in Chinese cities and construction of urban green ecological networks. Community greenway provides us with a new way of thinking on how to make future towns become into livable space combining nature and city. That is, connect community parks, street green patches, schools and major activity venues for residents with community greenways, and connect urban open space to form a corridor system network, in a way to disperse, dilute, mitigate and degrade PM2.5 [9]. So subarea-based construction, integrating the construction elements and injecting geographical and cultural connotations will is more effective strategy on planning and construction. To do so is not to simply connect public green areas and green space which can adjust the climate, but to change green infrastructure of urban environment, making green space protect the whole city area to build up more pleasant living environment for us. Hope we can work together!

\section{CONFLICT OF INTEREST}

The authors confirm that this article content has no conflict of interest.

\section{ACKNOWLEDGEMENTS}

The authors acknowledge the financial support by Education Department of Henan Province which provided three projects on humanities and social sciences issues. The first project (2013-GH-141) is "Study on the space model of community greenway to reduce PM2.5". The second project (2014-gh-208) is "Study on the planning and design model through integrating greenway and urban space". The third project (2014-DC-112) is "Study on optimization strategy and present situation of the greenway's space model in Zhengzhou".

\section{REFERENCES}

[1] Huang, J. Research on Community Greenway Design, Wuhan: Huazhong University of Science \& Technology, 2011.

[2] Li, Q.; Hu, J. Study on Post-evaluation for practice and application of Community Greenways, In: Proceedings of Annual National Planning Conference, China, 2011; pp. 3471-3479.

[3] Chen, F.; Ai, Y. Preliminary Study on Plan Schema for Greenway at Community Level, In: Proceedings of Urban Development \& Planning Conference, China, 2012; pp. 968-975.

[4] Yao, R. Research on the Guangzhou community greenway feasibility strategies. J. Guangdong Landscape Archit., 2012 34(188), pp. 12-14.

[5] Lai, S.; Zhu, J. Community greenway: a new trend of greenway practice in compact cities, Landscape Archit., 2012, 34, pp. 77-82.

[6] Hui, J.; Li, J.; Wang, Q.; Wang, C.; Liu, Z. Preliminary study on the container effect to reduce the PM2.5 pollution in the city residential-A case of the residential environment design inside the east gate, Xi'an. Architect. Culture, 2014, 2(119), pp. 120-122.

[7] Han, X. Construction of green roads for non-motor vehicles in urban communities of China. City Plan. Rev., 2003, 27(4), pp. 7174.

[8] Ye, Z. To Reduce PM2.5 concentration with construction of urban green space. Beijing Observation, 2013, (8), 21.

[9] Du, C. Thinking on PM2.5 Reducation with Green Infrastructure. Landscape Architect., 2012, 2, pp. 147.

\footnotetext{
Received: December 17, 2014

(C) Hao et al.; Licensee Bentham Open.

This is an open access article licensed under the terms of the Creative Commons Attribution Non-Commercial License (http://creativecommons.org/licenses/by-nc/3.0/) which permits unrestricted, non-commercial use, distribution and reproduction in any medium, provided the work is properly cited.
} 